Aquino, M. - O questionário como ferramenta de ensino

\title{
questionário como ferramenta de ensino de partículas modais alemãs
}

\author{
The questionnaire as a tool for teaching German modal particles \\ http://dx.doi.org/10.11606/1982-88372032156
}

Marceli Aquino ${ }^{1}$

\begin{abstract}
This work is an effort to collect relevant information about the decision making process on the communicative functions of the modal particles (henceforth MP), regarding different contexts. For this purpose, an online questionnaire was developed. For the data collection, sixty-two German native and non-native participants were asked to select from a set of sentences (with or without MPs) which provided the most adequate interpretations for preestablished contexts. The results suggest that native participants were more likely to select the expected options, but the reflections on the decisions taken were challenging for both groups. Therefore, data analysis indicates deficiencies in understanding the function and modal complexity of MPs. Thus, in addition to investigating the decision making process of both groups, we sought to offer tools for teaching MPs in German as a foreign language.
\end{abstract}

Keywords: German modal particles; German as a foreign language; relevance theory

Resumo: Este trabalho teve a intenção de investigar sobre o processo de tomada de decisão quanto às funções comunicativas das partículas modais (doravante PM), frente a diferentes contextos. Nesse sentido, aplicamos um questionário online em alemão. Para a coleta de dados foi solicitado a 62 participantes alemães nativos e não nativos que selecionassem dentre um conjunto de orações (contendo ou não PMs) as que proporcionariam interpretações adequadas para contextos pré-estabelecidos. Os resultados apontam que os participantes nativos tiveram maior facilidade em selecionar as opções esperadas nas tarefas apresentadas, porém as reflexões sobre as decisões tomadas foram desafiadoras para ambos os grupos. Portanto, a análise de dados indica deficiências na compreensão da função e complexidade modal das PMs. Assim, além de investigar as decisões tomadas pelos dois grupos, procuramos oferecer ferramentas para o ensino das PMs em aulas de alemão.

Palavras-chave: partículas modais alemãs; ensino de língua alemã; teoria da relevância

\footnotetext{
${ }^{1}$ Universidade de São Paulo, Faculdade de Filosofia, Letras e Ciências Humanas, Departamento de Letras Modernas, Av. Prof. Luciano Gualberto, 403, São Paulo, SP, 05508-010, Brasil. E-mail: marceli.c.aquino@gmail.com
} 


\section{Introdução}

As partículas modais (Modalpartikeln) são elementos lexicais, cujo uso tem como consequência a compreensão da fala com a manutenção do conteúdo semântico (KRIVONOSOV 1989:40-41). Elas funcionam como ferramentas para negociar inferências entre os interlocutores, ou seja, possibilitam reconhecer a atitude e intenção do emissor em relação à proposição expressada, e abrir espaço para a negociação de informações. Nesse sentido, as PMs denominam um aspecto interpessoal, gerando um clima conversacional específico ao enunciado, isto é, exprimem como cada participante da conversação se coloca em relação ao outro (WEYDT 1983:13).

Embora com diferentes definições, formas de análise e interpretação, fato é que as PMs representam um fenômeno típico da língua alemã por serem frequentes e extensivamente empregadas na interação (Helbig 1990:11). Consequentemente, o estudante da língua alemã, quando não incorpora as partículas, torna-se um falante do alemão rígido e atípico. BUSSE (1991: 39) afirma que a linguagem alemã sem partículas modais é claramente marcada por certa dureza, tornando-se uma língua áspera.

Segundo HERINGER (1988: 739), a grande dificuldade de descrição semântica das PMs advém da sua grande dependência contextual. O significado expressivo das PMsédiretamente influenciado pelo contexto, mas as questões topológicas também devem ser levadas em consideração (MöLLERING 2001).Os resultados de Aquino (2016), em pesquisa processual de tradução, demonstram a relevância da investigação desses elementos levando em consideração a sua disposição na oração. $O$ posicionamento da PM wohl influenciou diretamente nas decisões tradutórias dos participantes.

Não obstante, além do contexto e posicionamento, a investigação do significado das PMs deve ser essencialmente pautada nas funções nucleares específicas de cada PM. ${ }^{2}$ Logo, o significado das PMs precisa ser acessado por meio de distinções baseadas em parâmetros gramatical e semântico-lexical de cada PM em seu contexto de uso (ABRAHAM 1991a: 208). Defendemos, portanto, que cada partícula modal tem um significado núcleo que pode depender de uma variação de contexto ou nuance, ou seja, partem de uma análise lexical do contexto semântico.

\footnotetext{
${ }^{2}$ A PM doch, por exemplo, tem a função de indicar contradição a respeito de alguma situação ou informação. Já a PM wohl tem a função de sinalizar uma hipótese ou a falta de comprometimento com alguma informação.
} 
Aquino, M. - O questionário como ferramenta de ensino

A Teoria da Relevância (doravante TR) afirma que os seres humanos têm uma tendência automática para maximizar a relevância, não por escolha, mas em razão da forma como nossos sistemas cognitivos se desenvolveram. Nesse sentido, o princípio relevantista pode ser compreendido como uma relação de custo-benefício, baseada na premissa de que a cognição humana busca alcançar o maior efeito cognitivo através do menor esforço processual possível, promovendo quantidade, qualidade e organização do conhecimento do indivíduo (SPERBER; WILSON 1995: 465). Assim, a TR implica a avaliação sobre o grau de relevância de cada informação, isto é, a informação provável de provocar maior acréscimo de conhecimento com o menor custo de processamento.

Como resultado da constante necessidade de seleção na direção do aumento de eficiência, o sistema cognitivo humano estabeleceu-se de tal forma que nossos mecanismos perceptuais tendem automaticamente a escolher estímulos potencialmente relevantes (SPERBER; WILSON 2005: 227). Como as PMs fazem parte do ambiente cognitivo do falante de alemão, ele ou ela usam informações contextuais disponíveis em seu ambiente cognitivo para reconhecer imediatamente o significado pretendido, resultando em uma interpretação que alcance as expectativas de relevância, ou seja, uma relação adequada entre esforço e efeitos cognitivos (AQUINO 2017: 82-83).

Sendo elementos que fazem parte do ambiente cognitivo de nativos, as PMs são imediatamente reconhecidas e processadas. No entanto, a facilidade de compreender a intenção comunicativa das PMs na comunicação nem sempre é transferida no momento da tradução ou na tentativa de explicar sua função. Em AQUINO (2012a: 92), uma coleta realizada com brasileiros e alemães para sugerir legendas para filmes constatou que os alemães decidiam omitir a tradução das PMs com maior frequência em comparação com o grupo de brasileiros. Um resultado semelhante também foi obtido em Aquino (2016: 120), no qual, em tarefas de pós-edição, ${ }^{3}$ participantes alemães tendem a não processar as PMs e, durante protocolos verbais, comentaram não considerarem relevante representar a significação desses elementos para o português.

Por outro lado, o processamento desses elementos pode ser mais custoso para o falante não nativo, pois essas informações contextuais não estão totalmente acessíveis em seus ambientes cognitivos. Alguns trabalhos (DIEWALD 2013; FISCHER; ALM 2013; Franco 1991; Johnen 1997; KRÖll 1968; RAMOS 2000; SAID Ali 1930; TrAUgOTT 2007; WALTEREIT 2007; WELKER 1990), assumem a existência de partículas modais nas

\footnotetext{
${ }^{3}$ A pós-edição representa a revisão de um texto traduzido por um sistema de tradução automática.
} 
Aquino, M. - $\bigcirc$ questionário como ferramenta de ensino

línguas românicas, como o português. Esses estudos certamente apresentam tendências importantes na literatura, porém mesmo oferecendo alternativas para encontrar equivalentes em outras línguas, as características descritivas e as categorias gramaticais são distintas em alemão. ${ }^{4}$ Assim, parece plausível afirmar que partículas com as mesmas funções e características das PMs em alemão não são encontradas no português, dificultando então a compreensão desses elementos.

Com o intuito de explorar ferramentas para o ensino das PMs, SouZA (2008) investiga as características de língua falada em fóruns de discussão na internet. A pesquisadora avaliou principalmente as funções e as ações conversacionais da modalidade na comunicação online. Já MANOEL (1998) abordou por meio de um estudo de corpus as funções pragmáticas, semânticas e sintáticas das PMs, questionando sobre a dificuldade de aprendizado desses elementos no ensino de língua estrangeira. No sentido de oferecer alternativas tradutórias das PMs doch e ja para o ensino de língua, AQUINO (2012b: 105) apresenta os resultados de pesquisa baseada em diálogos de filmes alemães. Portanto, com a investigação de diferentes ferramentas didáticas, o professor não precisa depender apenas do livro didático, mas encontrar outros meios para apresentar as PMs para seus alunos.

Para melhor compreender sobre a função das PMs e como nativos(doravante $\mathrm{N}$ ) e não nativos (doravante $\mathrm{NN}$ ) justificam as suas escolhas em situações comunicativas, procuramos desenvolver uma coleta de dados por meio de um questionário online. $\mathrm{O}$ questionário em alemão (sem o processamento entre línguas) teve a intenção de proporcionar diferentes formas de uso das PMs, dentro de contextos variados. Após a escolha das soluções que consideravam adequadas, foi solicitado aos participantes que escrevessem justificativas para suas decisões. Como apontamos anteriormente, de acordo com o tipo de frase e a situação comunicativa, uma mesma PM pode expressar diferentes intenções comunicativas (NUNES 2008: 20-21). Portanto, foram selecionados diferentes contextos para abordar o uso e funções das PMs, procurando reproduzir situações reais do uso da língua.

Pela complexidade do processo inferencial envolvendo as PMs, era esperado que os participantes $\mathrm{N}$ selecionassem as sugestões esperadas, concordando com o enunciado original. Todavia, a representação desses elementos, a reflexão da função e do

\footnotetext{
${ }^{4}$ Em alemão as PMs representam uma classe gramatical homogênea, com distintas características sintáticas, semânticas e pragmáticas, que foram desenvolvidas diacronicamente, apresentando um status topológico restrito (ABRAHAM 1991b: 331).
} 
Aquino, M. - O questionário como ferramenta de ensino

significado, seria desafiadora para ambos os grupos. Além disso, a análise dos dez contextos incita discussões importantes para o ensino das partículas, evidenciando o benefício do uso de questionários como ferramenta para o desenvolvimento de atividades dinâmicas.

\section{Metodologia}

Este trabalho foi desenvolvido e aplicado durante o estágio de doutoramento da pesquisadora na Universidade Ludwig Maximilians Universität München (LMU). Os formulários do Google Drive tinham a finalidade de investigar empiricamente quais seriam as PMs utilizadas dentro de contextos controlados. Os participantes receberam dez contextos com quatro ou cinco opções com as PMs doch, wohl, aber e ja, e sem a presença desses elementos. A escolha de mais de uma opção era permitida.

Os questionários são conjuntos de questões com a finalidade de gerar dados para atingir objetivos de pesquisa (PARASURAMAN 1991). Além das questões de múltipla escolha, aplicamos perguntas abertas, a fim de estimular a cooperação dos participantes e viabilizar a compressão sobre as decisões tomadas. Mesmo de difícil quantificação, as justificativas complementam os resultados obtidos com as perguntas fechadas, auxiliando a interpretação da análise de dados. Além disso, a escolha de um modelo de investigação online se fundamenta pela oportunidade de recorrer a um maior número de pessoas, abrangendo características e perfis variados. A fim de acessar informações individuais, incluímos na coleta um formulário relativo ao perfil dos participantes.

As tarefas foram selecionadas por apresentar contextos simples e diversificados, reproduzindo situações reais de fala e permitindo a utilização de diferentes PMs em situações de uso e posições distintas. Os dez contextos foram retirados de diversas fontes: artigos jornalísticos das revistas online Stylebook, Yahoo e Spiegel; exemplos analisados nos artigos acadêmicos de ABRAHAM (1991b) "Discourse particles in German: How does their illocutive force come about?” e LINDNER (1991) “'Wir sind ja doch alte Bekannte'.The use of German ja and doch as modal particles".

Para a realização da pesquisa foram selecionados participantes de diversos perfis e nacionalidades. As 62 pessoas que responderam ao questionário são originárias da Alemanha, Áustria, Brasil, Bósnia, Cazaquistão, Espanha, Itália, Japão, Polônia, Rússia, 
Aquino, M. - O questionário como ferramenta de ensino

Turquia e Uzbequistão. Cada grupo (N e NN) abarcava31 membros. A proficiência em alemão dos NN se concentrava entre os níveis B2 e C1.

O perfil profissional e acadêmico dos participantes era bastante heterogêneo, abrangendo profissionais de língua alemã, como professores (universitários ou não) e estudantes (graduação e pós-graduação), professores, alunos e pesquisadores de outras áreas de conhecimento (física, engenharia, sociologia, nutrição etc.), estudantes de curso técnico e sem formação em ensino superior. Idade e sexo também eram variados. $\mathrm{O}$ propósito de integrar grupos tão heterogêneos era o de alcançar resultados diversificados, contando com um maior número de pessoas com perfis acadêmicos, sociais, linguísticos e regionais diferenciados. Portanto, para obter resultados relevantes e autênticos, investigamos as PMs em contextos que reproduzissem situações reais, sendo interpretados por participantes multifacetados.

O questionário foi realizado em plataforma online. A pesquisadora enviou os links, dois formulários do Google Drive, para cada participante. O primeiro continha Persönliche Informationen - informações pessoais - o segundo Forschungsfragebogen - questionário de pesquisa. Os participantes foram instruídos a responder os questionários na ordem enviada. Após a seleção da formulação desejada no questionário de pesquisa, o participante escrevia uma justificativa para explicar as escolhas tomadas.

\section{Análise e resultado}

A análise será dividida por tarefa. Apresentamos abaixo: os dez contextos com as opções (OP) oferecidas para escolha (a opção grifada representa a resposta esperada); os gráficos dos dados totais e por grupo $(\mathrm{N}$ e $\mathrm{NN})$, com a intenção de acessar a frequência de respostas; as tabelas com os temas mais recorrentes nas justificativas. ${ }^{5}$

\footnotetext{
${ }^{5}$ Os rótulos representam nomenclaturas próprias, que buscam alcançar maior clareza para o leitor ao resumir os comentários dos participantes: impressão, justificativa pautada na sensação ou sentimento; não sei, não sabiam explicar; correto, opção considerada correta (gramaticalmente ou impressão); sem/com $P M$, explicação sobre a escolha de opções com e sem PM; significado, análise do significado da oração com PM; posição, escolhas dependendo da posição da PM na oração; scopus, ênfase da PM; contexto, foco na análise contextual; informal, opção com conteúdo informal; aber, doch, ja, wohl, comentários voltados a discutir o significado e função das PM; wohlx, motivo pela exclusão desta PM das opções cabíveis; PM, discussão sobre as PMs; CG, common ground; todos, todas as opções seriam possíveis.
} 
Aquino, M. - O questionário como ferramenta de ensino

1. Matthew Cordle verursachte einen tödlichen Unfall, bei dem ein 61Jähriger starb. Der Polizei ist das bekannt, doch bisher wurde er nicht angeklagt. Nun hat der 22-Jährige alles auf YouTube gestanden.

OP1: Der Staatsanwalt wird Cordle am Montag wohl wegen fahrlässiger Tötung anklagen. OP2: Der Staatsanwalt wird wohl Cordle am Montag wegen fahrlässiger Tötung anklagen. OP3: Der Staatsanwalt wird Cordle wohl am Montag wegen fahrlässiger Tötung anklagen. OP4: Der Staatsanwalt wird Cordle am Montag wegen fahrlässiger Tötung anklagen.

Warum haben Sie sich für diese Formulierung(en) entschieden?

Figura 1: Contexto 1

Fonte: Marceli Aquino ${ }^{6}$

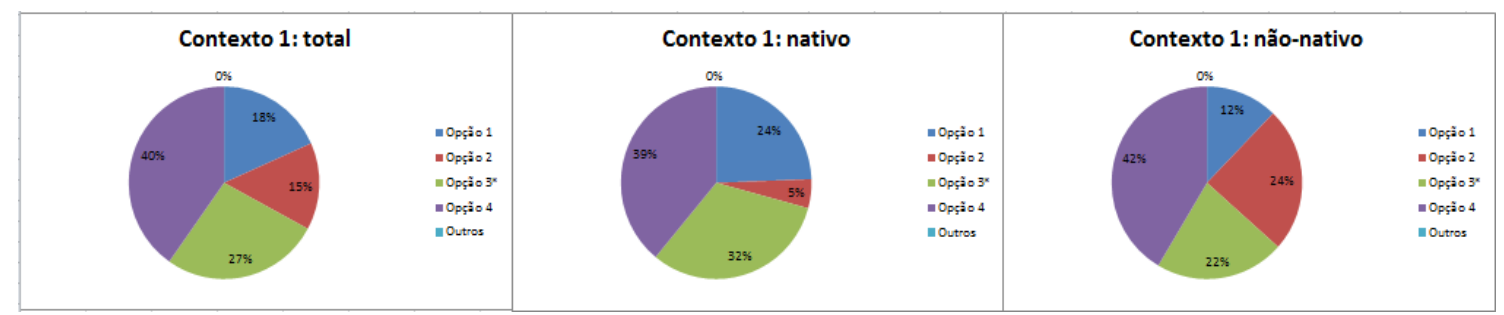

Gráfico 1: Porcentagem de escolhas totais e por grupo ( $\mathrm{N}$ e $\mathrm{NN}$ )

Fonte: Marceli Aquino

Tabela 1

Temas mais recorrentes nas justificativas de $\mathrm{N}$ e NN

\begin{tabular}{|c|c|c|c|c|c|c|c|c|c|}
\hline Participante & Impressão & Não sei & Correto & Sem PM & Significado & Posição & Scopus & Contexto & Informal \\
\hline NN & $\mathbf{1 1}$ & $\mathbf{4}$ & $\mathbf{6}$ & $\mathbf{2}$ & $\mathbf{4}$ & $\mathbf{1 1}$ & $\mathbf{3}$ & $\mathbf{1}$ & $\mathbf{3}$ \\
\hline$\%$ & $35.40 \%$ & $12.90 \%$ & $19.30 \%$ & $6.40 \%$ & $12.90 \%$ & $35.40 \%$ & $9.60 \%$ & $3.20 \%$ & $9.60 \%$ \\
\hline Opcão & $1,2,3,4$ & $1,2,4$ & $1,3,4$ & 4 & $2,3,4$ & $1,2,3,4$ & $\mathbf{2}$ & 3 & 1,4 \\
\hline $\mathbf{N}$ & $\mathbf{1 1}$ & $\mathbf{0}$ & $\mathbf{3}$ & $\mathbf{9}$ & $\mathbf{6}$ & $\mathbf{1 0}$ & $\mathbf{0}$ & $\mathbf{3}$ & $\mathbf{0}$ \\
\hline$\%$ & $35.40 \%$ & 0 & $9.60 \%$ & $29 \%$ & $19.30 \%$ & $32.20 \%$ & 0 & $9.60 \%$ & 0 \\
\hline Opcão & $1,2,3,4$ & 0 & 3,4 & 1,4 & $1,2,3,4$ & $1,2,3,4$ & 0 & $1,2,3,4$ & 0 \\
\hline Total & $\mathbf{2 2}$ & $\mathbf{4}$ & $\mathbf{9}$ & $\mathbf{1 1}$ & $\mathbf{1 0}$ & $\mathbf{2 1}$ & $\mathbf{3}$ & $\mathbf{4}$ & $\mathbf{3}$ \\
\hline \% Total & $\mathbf{3 5 \%}$ & $\mathbf{6 . 4 0} \%$ & $\mathbf{1 4 . 5 0} \%$ & $\mathbf{1 7 . 7 0} \%$ & $\mathbf{1 6 . 1 0} \%$ & $\mathbf{3 3 . 8 0} \%$ & $\mathbf{4 . 8 0} \%$ & $\mathbf{6 . 4 0 \%}$ & $\mathbf{4 . 8 0} \%$ \\
\hline Opção Total & $1,2,3,4$ & $1,2,4$ & $1,3,4$ & 1,4 & $1,2,3,4$ & $1,2,3,4$ & $\mathbf{2}$ & $1,2,3,4$ & 1,4 \\
\hline
\end{tabular}

Fonte: Marceli Aquino

Como apontado anteriormente, as respostas esperadas eram aquelas do texto original (PM e posição), e estão grifadas para destaque. O gráfico mostra que, no total, 27\% selecionaram a OP3 $(32 \% \mathrm{~N}, 22 \% \mathrm{NN})$. A OP4 foi a escolha com maior ocorrência, para ambos N (39\%) e NN (42\%). Como era permitida a escolhida de múltiplas opções para cada contexto, os participantes apresentaram uma inclinação pela seleção de orações com PM, juntamente com a versão sem esses elementos. Isso pode ser explicado pela insegurança na decisão, ou pelo fato de que enunciados sem PM são gramaticalmente corretos, mesmo que representando significações distintas.

\footnotetext{
${ }^{6}$ Todas as figuras, gráficos e tabelas deste trabalho foram elaborados pela autora da pesquisa.
} 
Aquino, M. - O questionário como ferramenta de ensino

A explicação mais recorrente nesse e em muitos contextos, referiu-se à impressão. Os participantes mencionaram que selecionaram a opção que parecia mais natural, mais comum ou que já haviam ouvido antes. Outro tema frequente destacava a diferença do significado da PM wohl dependendo da posição na frase (33,8\% total, 35,4\% NN e $32,2 \%$ N).Dependendo da representação que o participante tivesse do contexto, a PM poderia enfocar informações e intenções variadas.

Os resultados dessa tarefa poderiam suscitar o desenvolvimento de uma discussão em sala de aula sobre questões contextuais e topológicas para a compressão das PMs. Inicialmente seria recomendado ressaltar as restrições sintáticas das PMs, pois sua ocorrência é limitada ao Middle Field ou campo central. A divisão de campos (field) é uma característica da língua alemã e advém da separação da oração entre tema e rema. Logo, a posição das PMs deve ser trabalhada apenas dentro dessa estrutura. A partir de questões estruturais, pode-se discutir as diferentes ênfases e funções das PMs em uma mesma oração, levando em consideração as inferências contextuais, funções nucleares e a relação entre os interlocutores.

2. Zwei Freundinnen, Anna und Julia, sind an der Bushaltestelle. Es ist schon spät, sodass kein Bus mehr fährt. Anna ist verzweifelt, sie weiß nicht genau, was sie tun sollen. Julia ist ungeduldig und sagt ganz ironisch, dass Anna laufen kann.

OP1: Du kannst laufen.

OP2: Du kannst doch laufen.

OP3: Du kannst wohl laufen.

OP4: Du kannst ja laufen.

Warum haben Sie sich für diese Formulierung(en) entschieden?

Figura 2: Contexto 2

Fonte: Marceli Aquino

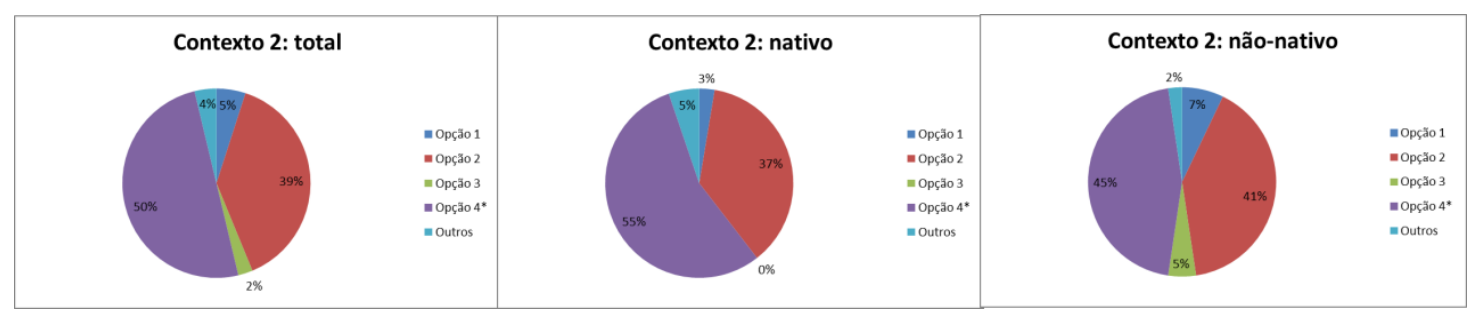

Gráfico 2: Porcentagem de escolhas totais e por grupo ( $\mathrm{N}$ e $\mathrm{NN})$

Fonte: Marceli Aquino 
Aquino, M. - O questionário como ferramenta de ensino

Tabela 2

Temas mais recorrentes nas justificativas de $\mathrm{N}$ e NN

\begin{tabular}{|c|c|c|c|c|c|c|c|c|c|}
\hline Participante & Impressão & Wohl & Doch & $\mathrm{Ja}$ & PM & Sem PM & CG & Contexto & Informal \\
\hline NN & 8 & 1 & 6 & 10 & 5 & 1 & 3 & 1 & 3 \\
\hline$\%$ & $28.50 \%$ & $3.20 \%$ & $19.30 \%$ & $32.20 \%$ & $16.10 \%$ & $3.20 \%$ & $9.60 \%$ & $3.20 \%$ & $9.60 \%$ \\
\hline Opcão & 2,4 & 3 & 2,4 & 2,4 & $1,2,3,4$ & 1 & $2,4,5$ & $1,2,4$ & 2,4 \\
\hline $\mathbf{N}$ & 11 & 0 & 4 & 10 & 12 & 0 & 2 & 0 & 0 \\
\hline$\%$ & $35.40 \%$ & 0 & $12.90 \%$ & $32.20 \%$ & $38.70 \%$ & 0 & $6.40 \%$ & 0 & 0 \\
\hline Opcão & $1,2,4$ & 0 & 2 & 4 & $2,4,5$ & 0 & 2,4 & 0 & 0 \\
\hline Total & 19 & 1 & 10 & 20 & 17 & 1 & 5 & 1 & 3 \\
\hline \% Total & $31 \%$ & $1.60 \%$ & $16.00 \%$ & $32.20 \%$ & $27.40 \%$ & $1.60 \%$ & $8.00 \%$ & $1.60 \%$ & $4.80 \%$ \\
\hline Opção Total & $1,2,4$ & 3 & 2,4 & 2,4 & $1,2,3,4$ & 1 & $2,4,5$ & $1,2,4$ & 2,4 \\
\hline
\end{tabular}

Fonte: Marceli Aquino

A resposta esperada, $\mathrm{OP} 4$ com $\mathrm{PM} j a$, foi preferida pela maioria dos participantes $(50 \%$ total, $55 \%$ N, $45 \%$ NN). Dependendo da intenção do emissor, a OP2, que foi a segunda mais selecionada, também poderia ter sido adequada. De acordo com LINDNER (1991: 193), as PMs doch e ja têm funções elocutórias e semânticas semelhantes e, por isso, são comumente utilizadas em combinação ( $j a$ doch, nessa ordem). Além disso, elas ocorrem geralmente em tipos parecidos de orações (asserções e exclamações). Ambas conseguem estabelecer uma negociação de informações relevantes para a manutenção do conteúdo semântico, facilitando a interação.

Ademais, essas PMs são abundantemente analisadas na literatura e no ensino de alemão. Por serem partículas recorrentes no discurso, pela sua semelhança semântica, por aparecerem em tipos de orações similares e pela ocorrência em combinação, elas poderiam ser trabalhadas juntas em sala de aula. Exemplos como o apresentado acima podem ser utilizados para explicar suas semelhanças e diferenças, dependendo do contexto e da intenção na interação.

As justificativas focaram principalmente na impressão. Porém, outra explicação recorrente pautou-se na interpretação da função da PM escolhida. Os participantes afirmaram que as PMs doch e ja expressavam ironia e provocação. Ademais, comentários sobre a dependência da análise contextual também foram manifestados.

Segundo os postulados da TR, um input (um enunciado, uma memória) é relevante quando é capaz de conectar as informações de um background de modo a produzir resultados importantes a um indivíduo, seja para esclarecer uma dúvida, aumentar o conhecimento sobre um assunto, confirmar suspeitas, corrigir uma informação equivocada, adquirir e/ou relembrar uma informação etc. Pelo viés da TR, as PMs representam um input relevante, uma vez que com elas é possível acessar o conhecimento entre o emissor e o receptor e derivar a implicação contextual necessária. 
Aquino, M. - $\bigcirc$ questionário como ferramenta de ensino

Nesse sentido, as PMs funcionariam como pistas comunicativas, fornecendo evidência de sua intenção de comunicar um certo significado, que é inferido pela audiência com base na evidência fornecida (SPERBER; WILSON 2005: 221).

Então, as justificativas apresentadas nessa tarefa estão de acordo com as expectativas deste trabalho, dado que as PMs funcionam como pistas de acesso às representações mentais necessárias para a negociação de informações relevantes no enunciado. Portanto, a escolha da PM sinaliza a atitude do emissor e as expectativas dos interlocutores com relação à proposição. Nesse contexto, a personagem não queria dizer que a amiga tinha a capacidade motora de caminhar, mas enfatizar ironicamente a sua impaciência com conduta da amiga, exigindo mudanças de comportamento.

3. Karin hat am Donnerstag einen Brief an Leo abgeschickt. Es ist schon Dienstag und er hat immer noch nicht geantwortet. Karin ist deswegen sehr neugierig. Sie fragt sich, ob Leo den Brief schon bekommen hat oder nicht.

OP1: Ob er meinen Brief wohl noch nicht bekommen hat?

$\mathrm{OP} 2$ : Ob er meinen Brief noch nicht bekommen hat?

OP3: Ob er meinen Brief doch noch nicht bekommen hat?

OP4: Ob er meinen Brief ja noch nicht bekommen hat?

Warum haben Sie sich für diese Formulierung(en) entschieden?

Figura3: Contexto 3

Fonte: Marceli Aquino

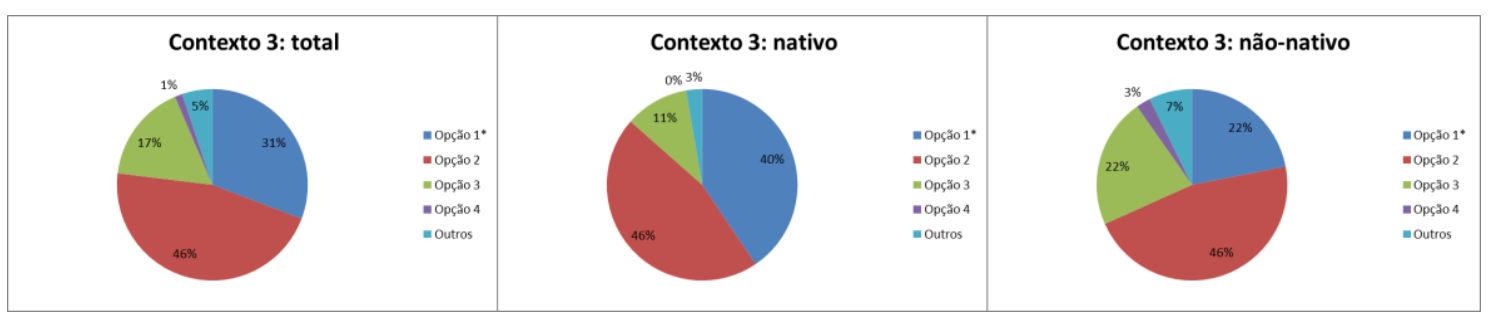

Gráfico 3: Porcentagem de escolhas totais e por grupo (N e NN)

Fonte: Marceli Aquino

Tabela 3

Temas mais recorrentes nas justificativas de $\mathrm{N}$ e NN

\begin{tabular}{|c|c|c|c|c|c|c|c|c|c|}
\hline & & & & & & & \\
Participante & Impressão & Não sei & Correto & Todos & Sem PM & Contexto & Informal & Doch & Wohl \\
\hline NN & $\mathbf{9}$ & $\mathbf{3}$ & $\mathbf{2}$ & $\mathbf{1}$ & $\mathbf{4}$ & $\mathbf{1}$ & $\mathbf{1}$ & $\mathbf{7}$ & $\mathbf{4}$ \\
\hline$\%$ & $29 \%$ & $9.60 \%$ & $6.40 \%$ & $3.20 \%$ & $12.90 \%$ & $3.20 \%$ & $3.20 \%$ & $22.50 \%$ & $12.90 \%$ \\
\hline Opcão & $1,2,3$ & $2,3,4$ & & $1,2,3$ & 1,2 & $1,2,3$ & 1,2 & $1,2,3$ & $1,2,3$ \\
\hline $\mathbf{N}$ & $\mathbf{9}$ & $\mathbf{2}$ & $\mathbf{1}$ & $\mathbf{1}$ & $\mathbf{6}$ & $\mathbf{1}$ & $\mathbf{0}$ & $\mathbf{5}$ & $\mathbf{1 0}$ \\
\hline$\%$ & $29 \%$ & $6.40 \%$ & $3.20 \%$ & $3.20 \%$ & $6.40 \%$ & $3.20 \%$ & 0 & $16.10 \%$ & $32.20 \%$ \\
\hline Opcão & 1,2 & 1,2 & & $1,2,3$ & 1,2 & $\mathbf{2}$ & 0 & $1,2,3$ & $1,2,3$ \\
\hline Total & $\mathbf{1 8}$ & $\mathbf{5}$ & $\mathbf{3}$ & $\mathbf{2}$ & $\mathbf{1 0}$ & $\mathbf{2}$ & $\mathbf{1}$ & $\mathbf{1 2}$ & $\mathbf{1 4}$ \\
\hline \% Total & $\mathbf{2 9} \%$ & $\mathbf{8 . 0 0} \%$ & $\mathbf{4 . 8 0} \%$ & $\mathbf{3 . 2 0} \%$ & $\mathbf{1 6 . 0 0 \%}$ & $\mathbf{3 , 2} \%$ & $\mathbf{1 . 6 0 \%}$ & $\mathbf{1 9 , 3} \%$ & $\mathbf{2 2 . 5 0 \%}$ \\
\hline Opção Total & $1,2,3$ & $1,2,3,4$ & $\mathbf{2}$ & $1,2,3$ & 1,2 & $1,2,3$ & 1,2 & $1,2,3$ & $1,2,3$ \\
\hline
\end{tabular}

Fonte: Marceli Aquino 
A resposta esperada (OP1), com PM wohl, apresentou $31 \%$ das escolhas (40\% N, $22 \%$ $\mathrm{NN}$ ), contra 46\% (N e NN) da OP2 sem PM. Na justificativa, os que optaram pela formulação sem PM afirmaram que o contexto não pedia o uso de uma PM (16\% das justificativas). Todavia, muitos desses participantes também selecionaram a OP1 com PM wohl. Aqueles que elegeram a opção com wohl explicaram que a PM tinha a função de indicar incerteza quanto à chegada da carta: o emissor tenta justificar a falta de uma resposta com a hipótese de que a carta não foi recebida.

A PM wohl é frequentemente traduzida como sinônimo de wahrscheinlich (“provavelmente"). No entanto, sabemos que na maioria dos casos (como no exemplo acima), essa PM tem função diferente de wahrscheinlich. Enquanto wohl requer que uma hipótese ou um conhecimento anterior sejam acessíveis aos indivíduos envolvidos na comunicação, wahrscheinlich não apresenta nenhuma restrição contextual. Dessa maneira, nem sempre wohl se refere à probabilidade, mas sim à hipótese, suposição ou afirmação fraca. Casos de wohl podem ser trabalhados em sala de aula com o auxílio de exemplos que possibilitem analisar sua função em diferentes contextos.

4. Heidi Klum zeigt sich gerne nackt - na und? Wem das nicht gefällt, der soll sie bei Facebook einfach entliken, so die Meinung des Topmodels. Immer wieder musste sich Heidi Klum deshalb fiese Negativ-Kommentare gefallen lassen. Nun schlägt Heidi zurück! Im Gespräch mit „Access Hollywood“ macht das Topmodel eine klare Ansage in Richtung Hater:

OP1: „Wer damit nicht umgehen kann, der soll mir einfach nicht mehr folgen!““. OP2: „Wer damit nicht umgehen kann, der soll mir doch einfach nicht mehr folgen!“. OP3: „Wer damit nicht umgehen kann, der soll mir wohl einfach nicht mehr folgen!“‘. OP4: „Wer damit doch nicht umgehen kann, der soll mir einfach nicht mehr folgen!“‘. OP5: „Wer damit wohl nicht umgehen kann, der soll mir einfach nicht mehr folgen!“.

Warum haben Sie sich für diese Formulierung(en) entschieden?

Figura4: Contexto 4

Fonte: Marceli Aquino

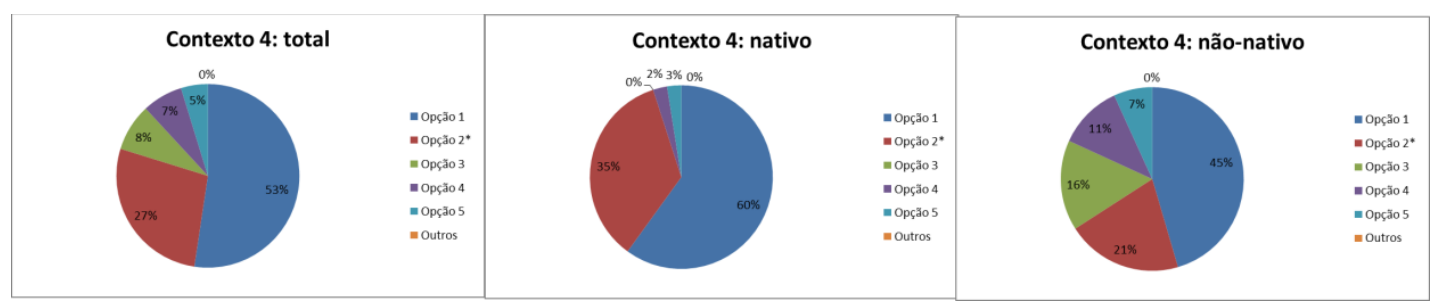

Gráfico 4: Porcentagem de escolhas totais e por grupo ( $\mathrm{N}$ e $\mathrm{NN})$

Fonte: Marceli Aquino 
Aquino, M. - O questionário como ferramenta de ensino

Tabela 4

Temas mais recorrentes nas justificativas de $\mathrm{N}$ e NN

\begin{tabular}{|c|c|c|c|c|c|c|c|c|c|}
\hline Participante & Impressão & Não sei & Correto & Todos & Sem PM & Informal & Doch 1 & Doch_II & Wohl \\
\hline NN & $\mathbf{1 1}$ & $\mathbf{2}$ & $\mathbf{2}$ & $\mathbf{1}$ & $\mathbf{6}$ & $\mathbf{1}$ & $\mathbf{1}$ & $\mathbf{5}$ & $\mathbf{4}$ \\
\hline$\%$ & $35.40 \%$ & $6.40 \%$ & $6.40 \%$ & $3.20 \%$ & $19.30 \%$ & $3.20 \%$ & $3.20 \%$ & $16.10 \%$ & $12.90 \%$ \\
\hline Opcão & $1,2,3,4$ & $2,4,5$ & 1 & $1,2,3,4$ & 1,5 & 2,4 & 4 & $1,2,3,4$ & $1,2,3,4$ \\
\hline $\mathbf{N}$ & $\mathbf{1 3}$ & $\mathbf{0}$ & $\mathbf{2}$ & $\mathbf{0}$ & $\mathbf{9}$ & $\mathbf{0}$ & $\mathbf{1}$ & $\mathbf{1 0}$ & $\mathbf{1}$ \\
\hline$\%$ & $41.90 \%$ & 0 & $6.40 \%$ & 0 & $29 \%$ & 0 & $3.20 \%$ & $32.20 \%$ & $3.20 \%$ \\
\hline Opcão & 1,2 & 0 & 1 & 0 & 1,2 & 0 & 4 & $1,2,5$ & 1,2 \\
\hline Total & $\mathbf{2 4}$ & $\mathbf{2}$ & $\mathbf{4}$ & $\mathbf{1}$ & $\mathbf{1 5}$ & $\mathbf{1}$ & $\mathbf{2}$ & $\mathbf{1 5}$ & $\mathbf{5}$ \\
\hline \% Total & $\mathbf{3 8 . 7 0} \%$ & $\mathbf{3 . 2 0} \%$ & $\mathbf{6 . 4 0 \%}$ & $\mathbf{1 . 6 0} \%$ & $\mathbf{2 4 . 2 0} \%$ & $\mathbf{1 . 6 0}$ & $\mathbf{3 , 3} \%$ & $\mathbf{2 4 . 2 0 \%}$ & $\mathbf{8} \%$ \\
\hline Opção Total & $1,2,3,4$ & $2,4,5$ & 1 & $1,2,3,4$ & $1,2,5$ & 2,4 & 4 & $1,2,3,4$ & $1,2,3,4$ \\
\hline
\end{tabular}

Fonte: Marceli Aquino

A OP2, com PM doch na segunda posição, isto é, na segunda oração, foi preferida $27 \%$ das vezes $(35 \% \mathrm{~N}, 21 \% \mathrm{NN})$, perdendo apenas para a OP1 sem PM (53\%total, $60 \% \mathrm{~N}$, $45 \% \mathrm{NN}$ ). Nesse contexto, a justificativa mais citada recaía no tema impressão $(38,7 \%$ total, $41,9 \% \mathrm{~N}, 35,4 \% \mathrm{NN})$. A reflexão quanto à $\mathrm{OP} 1$ foi fundamentada pela dispensabilidade de utilizar PMs nesse contexto. Novamente, em alguns casos a preferência pela opção sem PM acompanhou formulações com PMs, especificamente as OP5 e OP2.

A escolha da PM doch na OP2 foi justificada por oferecer força e evidência à oração. Nesse contexto, a PM funcionaria como ferramenta para evidenciara atitude e a intenção da personagem. A PM doch tem função de contradição no ambiente cognitivo dos interlocutores, acentuando que algo não foi levado em consideração. Os nativos foram os que melhor refletiram sobre essa função $(32,2 \% \mathrm{~N}, 16,1 \% \mathrm{NN})$, o que demonstra um maior nível de expertise no uso e compreensão da PM doch. Portanto, destacamos mais uma vez a necessidade de explorar as funções nucleares das PMs, como ponto inicial de ensino desses elementos.

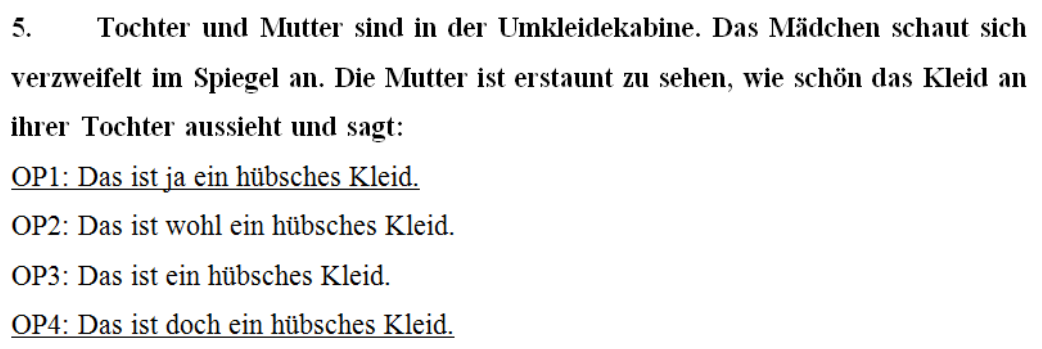

Warum haben Sie sich für diese Formulierung(en) entschieden?

Figura 5: Contexto 5

Fonte: Marceli Aquino 
Aquino, M. - O questionário como ferramenta de ensino

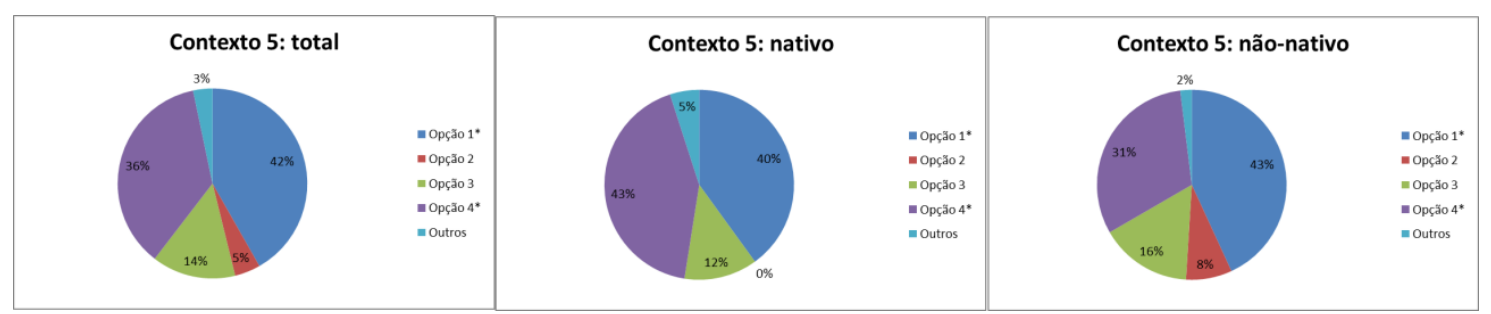

Gráfico 5: Porcentagem de escolhas totais e por grupo (N e NN)

Fonte: Marceli Aquino

Tabela 5

Temas mais recorrentes nas justificativas de $\mathrm{N}$ e NN

\begin{tabular}{|c|c|c|c|c|c|c|c|}
\hline Participante & Impressão & Correto & Todos & Sem PM & $\mathrm{Ja}$ & Doch & Wohl \\
\hline NN & 5 & 1 & 5 & 2 & 15 & 9 & 2 \\
\hline$\%$ & $16.10 \%$ & $3.20 \%$ & $16.10 \%$ & $6.40 \%$ & $48.30 \%$ & $29 \%$ & $6.40 \%$ \\
\hline Opcão & $1,3,4$ & 3 & $1,2,3,4$ & 3 & $1,2,4,5$ & $1,3,4$ & $1,2,3,4$ \\
\hline $\mathbf{N}$ & 6 & 0 & 0 & 0 & 12 & 16 & 1 \\
\hline$\%$ & $19.30 \%$ & 0 & 0 & 0 & $38.70 \%$ & $51.60 \%$ & $3.20 \%$ \\
\hline Opcão & $1,3,4$ & 0 & 0 & 0 & $1,3,4,5$ & 1,4 & 1,3 \\
\hline Total & 11 & 1 & 5 & 2 & 27 & 25 & 3 \\
\hline \% Total & $17.70 \%$ & $1.60 \%$ & $8 \%$ & $3.20 \%$ & $43.50 \%$ & $40.30 \%$ & $4.80 \%$ \\
\hline Opção Total & $1,3,4$ & 3 & $1,2,3,4$ & 3 & $1,2,3,4,5$ & $1,3,4$ & $1,2,3,4$ \\
\hline
\end{tabular}

Fonte: Marceli Aquino

Esse contexto aceitava duas possibilidades de respostas, aOP1 com ja e OP4 com doch. A formulação mais selecionada foi a OP1 (42\% total, $40 \% \mathrm{~N}, 43 \% \mathrm{NN})$, e a segunda a OP4(36\% total, $\mathrm{N} 43 \%$, NN 31\%). As justificativas para essas escolhas foram relativamente semelhantes, nas quais os participantes apontaram que as PMs ja e doch adquiriram, nesse contexto, a função de sinalizar surpresa e até estupefação. Esse resultado é compatível com o encontrado no contexto 2, no qual duas PMs poderiam ser utilizadas no mesmo enunciado, dependendo da interpretação contextual. Logo, essa seria outra tarefa que serviria como ferramenta para explorar as duas PM mencionadas.

Como o tema surpresa foi reportado na tarefa, seria pertinente descrever a função de surpresa e adversidade da PM aber em diferentes contextos. Nos princípios da TR, o contexto configura-se a partir das características do ambiente cognitivo de um determinado indivíduo e, consequentemente, está em constante modificação. Para SPERBER e WILSON (1995), o contexto emerge a partir das informações conscientes de um indivíduo, mas pode ser enriquecido por outras informações das quais esse mesmo indivíduo venha a se conscientizar. Assim, dependendo de informações anteriores (por exemplo, a filha nunca usa vestido) ou da atitude da mãe e da filha (por exemplo, a filha se achou feia no vestido, a mãe quer evidenciar o elogio), diferentes PMs podem ser utilizadas para representar tais informações a serem processadas. 
Aquino, M. - $\bigcirc$ questionário como ferramenta de ensino

6. Oli ist wütend auf Ben. Ben ist enttäuscht und versucht Oli davon zu überzeugen, ihm zu vergeben, denn schließlich kennen sie sich schon lange. Oli erkennt zwar die alte Freundschaft, aber für ihn reicht das nicht. Daher versucht er mit Nachdruck Oli von der Freundschaft zu überzeugen, indem er sagt:

OP1: Wir sind wohl alte Bekannte!

OP2: Wir sind alte Bekannte!

OP3: Wir sind doch alte Bekannte!

OP4: Wir sind ja alte Bekannte!

Warum haben Sie sich für diese Formulierung(en) entschieden?

Figura 6: Contexto 6

Fonte: Marceli Aquino

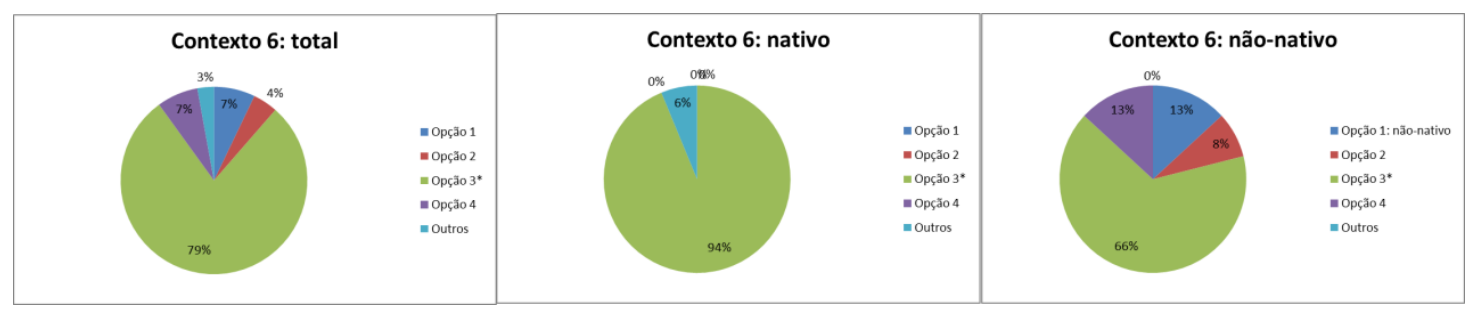

Gráfico 6: Porcentagem de escolhas totais e por grupo ( $\mathrm{N}$ e $\mathrm{NN})$

Fonte: Marceli Aquino

Tabela 6

Temas mais recorrentes nas justificativas de $\mathrm{N}$ e NN

\begin{tabular}{|c|c|c|c|c|c|c|c|c|c|c|}
\hline Participante & Impressão & Não sei & Correto & Todos & Sem PM & Contexto & Informal & Doch & Wohl & Ja \\
\hline NN & $\mathbf{6}$ & $\mathbf{4}$ & $\mathbf{1}$ & $\mathbf{2}$ & $\mathbf{1}$ & $\mathbf{0}$ & $\mathbf{2}$ & $\mathbf{1 4}$ & $\mathbf{3}$ & $\mathbf{2}$ \\
\hline$\%$ & $19.30 \%$ & $12.90 \%$ & $3.20 \%$ & $6.40 \%$ & $3.20 \%$ & 0 & $6.40 \%$ & $45.10 \%$ & $9.60 \%$ & $6.40 \%$ \\
\hline Opcão & 3,4 & 3 & 3 & $1,2,3,4$ & 2 & 0 & 2,3 & $1,3,4$ & 1,3 & 3.4 \\
\hline $\mathbf{N}$ & $\mathbf{8}$ & $\mathbf{1}$ & $\mathbf{1}$ & $\mathbf{0}$ & $\mathbf{0}$ & $\mathbf{2}$ & $\mathbf{0}$ & $\mathbf{2 1}$ & $\mathbf{0}$ & $\mathbf{0}$ \\
\hline$\%$ & $25.80 \%$ & $3.20 \%$ & $3.20 \%$ & 0 & 0 & $6.40 \%$ & 0 & $67.70 \%$ & 0 & 0 \\
\hline Opcão & 3 & 3 & 3 & 0 & 0 & 3 & 0 & 3 & 0 & 0 \\
\hline Total & $\mathbf{1 4}$ & $\mathbf{5}$ & $\mathbf{2}$ & $\mathbf{2}$ & $\mathbf{1}$ & $\mathbf{2}$ & $\mathbf{2}$ & $\mathbf{3 5}$ & $\mathbf{3}$ & $\mathbf{2}$ \\
\hline \% Total & $\mathbf{2 2 . 5 0} \%$ & $\mathbf{8} \%$ & $\mathbf{3 . 2 0} \%$ & $\mathbf{3 . 2 0} \%$ & $\mathbf{1 . 6 0} \%$ & $\mathbf{3 . 2 0} \%$ & $\mathbf{3 . 2 0} \%$ & $\mathbf{5 6 . 4 0 \%}$ & $\mathbf{4 . 8 0} \%$ & $\mathbf{3 . 2 0} \%$ \\
\hline Opção Total & 3 & 3 & 3 & $1,2,3,4$ & $\mathbf{2}$ & 3 & 2,3 & $1,3,4$ & 1,3 & 3,4 \\
\hline
\end{tabular}

Fonte: Marceli Aquino

Esse contexto apresentou soluções homogêneas, visto que $79 \%$ dos participantes escolheram a OP3 com doch $(94 \% \mathrm{~N}, 66 \% \mathrm{NN})$. A segunda colocação ficou entre a OP1 com wohl (total 7\%) e a OP4 com ja (total 7\%). As justificativas recaem sobre a função da PM doch no contexto (56,4\%total, $67,7 \% \mathrm{~N}, 45,1 \% \mathrm{NN})$, isto é, sinalizar contradição e convencimento. Ao utilizar a PM doch o emissor tenta convencer o receptor a considerar uma informação como relevante, ou seja, que apesar dos problemas eles são velhos amigos, e isso deveria ser suficiente para que o ouvinte o perdoasse.

Nos termos da TR, em contextos idênticos, quanto maiores forem os efeitos cognitivos positivos alcançados pelo processamento de um input, maior será a 
Aquino, M. - $\bigcirc$ questionário como ferramenta de ensino

relevância. Assim, a PM doch funciona como uma instrução para que o receptor acesse seu ambiente cognitivo na busca de informações anteriores, que devem ser consideradas no momento da enunciação. O significado precisa ser negociado entre os indivíduos, mesmo não estando em comum acordo.

Como esse exemplo apresenta um caso de grande concordância interpretativa entre os participantes, ele poderia ser utilizado como atividade em aulas iniciais de alemão com temática de PMs. O contexto, o vocabulário e o uso da PM são bastante acessíveis, podendo facilitar a compreensão da sua função.

7. Lorena und Theo sind ein Paar und wohnen zusammen. Lorena hat eine
schlimme Erkältung, aber sie möchte trotzdem draußen joggen. Es regnet
Bindfäden. Theo ist besorgt und warnt sie vor dem Regen und der Nässe.

OP1: Es regnet!

OP2: Es regnet wohl!

OP3: Es regnet doch!

OP4: Es regnet aber!

Warum haben Sie sich für diese Formulierung(en) entschieden?

Figura 7: Contexto 7

Fonte: Marceli Aquino

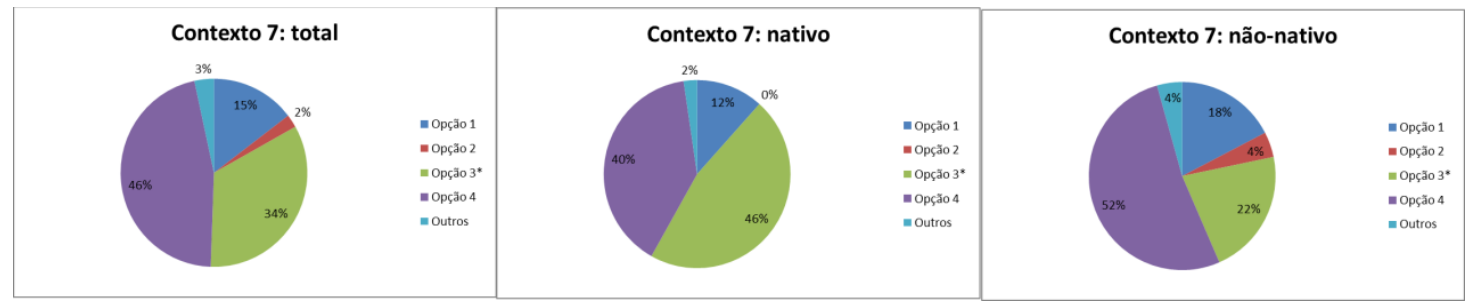

Gráfico 7: Porcentagem de escolhas totais e por grupo (N e NN)

Fonte: Marceli Aquino

Tabela 7

Temas mais recorrentes nas justificativas de $\mathrm{N}$ e NN

\begin{tabular}{|c|c|c|c|c|c|c|c|c|}
\hline Participante & Impressão & Não sei & Sem PM & Contexto & Doch & Wohl & Wohl X & Aber \\
\hline NN & 9 & 4 & 3 & 5 & 4 & 2 & 1 & 18 \\
\hline$\%$ & $29 \%$ & $12.90 \%$ & $9.60 \%$ & $16.10 \%$ & $12.90 \%$ & $6.40 \%$ & $3.20 \%$ & $58 \%$ \\
\hline Opcão & $1,3,4,5$ & $1,2,3,4$ & 1,2 & $1,2,3,4$ & $1,2,3,4,5$ & $1,2,3,4$ & 1,3 & $1,2,3,4, S$ \\
\hline $\mathbf{N}$ & 10 & 2 & 2 & 0 & 13 & 0 & 2 & 10 \\
\hline$\%$ & $32.20 \%$ & $6.40 \%$ & $6.40 \%$ & 0 & $41.90 \%$ & 0 & $6.40 \%$ & $32.20 \%$ \\
\hline Opcão & $1,3,4$ & 3,4 & 1,3 & 0 & $1,3,4$ & 0 & 1,4 & $1,3,4$ \\
\hline Total & 19 & 6 & 5 & 5 & 17 & 2 & 3 & 28 \\
\hline \% Total & $30.60 \%$ & $9.60 \%$ & $8 \%$ & $8 \%$ & $27.40 \%$ & $3.20 \%$ & $4.80 \%$ & $45.10 \%$ \\
\hline Opção Total & $1,3,4,5$ & $1,2,3,4$ & $1,2,3$ & $1,2,3,4$ & $1,2,3,4,5$ & $1,2,3,4$ & $1,3,4$ & $1,2,3,4, S$ \\
\hline
\end{tabular}

Fonte: Marceli Aquino 
Aquino, M. - O questionário como ferramenta de ensino

A opção mais frequente foi a OP4 com PM aber $(46 \%$ total, $40 \% \mathrm{~N}, 52 \% \mathrm{NN})$. A análise das justificativas indicou que essa formulação foi selecionada por uma confusão causada pela conjunção adversativa mas no contexto. Os participantes escolheram essa alternativa pela interpretação de oposição, que representa a função da conjunção e não do modal aber. Podemos afirmar, então, que a formulação do texto teve impacto direto nas decisões. Vale evidenciar que o nível de expertise na língua tem um papel importante nessa escolha, já que a OP3 foi escolhida em grande parte por N (52\%). Além disso, $46 \%$ dos $\mathrm{N}$ escolheram a opção esperada em comparação com $22 \%$ dos NN.

Esse contexto, como os outros aplicados no questionário, oferece uma rica oportunidade para discussões e trabalhos em sala de aula sobre a função modal desses elementos. As atividades podem enfocar no contraste entre as PMs e seus homônimos não modais, como conjunções e advérbios. Sobre uma perspectiva diacrônica, o significado das PMs é derivado, direta ou indiretamente, de seu homônimo de categorias não pertencentes à das PMs. Segundo ABRAHAM (1991a: 209), para obter o significado de uma PM é necessário um processo de reconstrução, que deve contar com uma leitura referencial do elemento lexical homônimo à PM levando em conta o seu uso no contexto.

Além disso, como mencionado nas outras tarefas, os exemplos deste questionário oferecem uma base bastante relevante e dinâmica para desenvolver a discussão da função nuclear de cada partícula, e sua possível significação em determinados contextos, como no caso de doch e aber nessa tarefa.

\footnotetext{
8. Die besten Flirt-Sportarten: Im Fitnessstudio müssen Sie nicht mal besonders schlagfertig sein - Sie bekommen quasi andauernd eine neue Chance, sofern ihr Flirtobjekt regelmäßig trainiert. Das ist Flirten frei Haus: Sie könnten über ein Gerätetraining sprechen, Hilfe bei einer Einstellung am Gerät benötigen oder in der Sauna nackte Tatsachen ausspionieren.

OP1: Das Fitnessstudio ist der beste Ort, an dem man die Möglichkeit hat mit Menschen in Kontakt zu kommen.

OP2: Das Fitnessstudio ist doch der beste Ort, an dem man die Möglichkeit hat mit Menschen in Kontakt zu kommen.

OP3: Das Fitnessstudio ist wohl der beste Ort, an dem man die Möglichkeit hat mit Menschen in Kontakt zu kommen.

OP4: Das Fitnessstudio ist der beste Ort, an dem man doch die Möglichkeit hat mit Menschen in Kontakt zu kommen.

OP5: Das Fitnessstudio ist der beste Ort, an dem man wohl die Möglichkeit hat mit Menschen in Kontakt zu kommen.

Warum haben Sie sich für diese Formulierung(en) entschieden?
}

Figura 8: Contexto 8

Fonte: Marceli Aquino 
Aquino, M. - O questionário como ferramenta de ensino

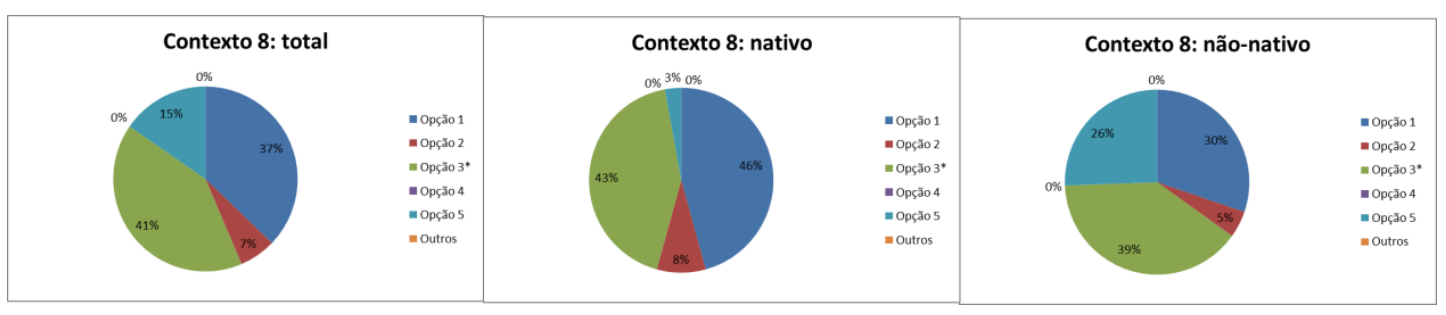

Gráfico 8: Porcentagem de escolhas totais e por grupo (N e NN)

Fonte: Marceli Aquino

Tabela 8

Temas mais recorrentes nas justificativas de $\mathrm{N}$ e NN

\begin{tabular}{|c|c|c|c|c|c|c|c|c|c|}
\hline Participante & Impressão & Não sei & Com PM & Sem PM & Correto & Contexto & Doch 1 & Wohl 1 & Wohl 2 \\
\hline NN & 9 & 5 & 1 & 3 & 3 & 3 & 0 & 10 & 8 \\
\hline$\%$ & $29 \%$ & $16.10 \%$ & $3.20 \%$ & $9.60 \%$ & $9.60 \%$ & $9.60 \%$ & 0 & $32.20 \%$ & $25.80 \%$ \\
\hline Opcão & $1,2,3,5$ & $1,3,5$ & $1,3,5$ & 1 & 1,5 & $1,3,5$ & 0 & $1,3,5$ & $1,3,5$ \\
\hline $\mathbf{N}$ & 12 & 2 & 2 & 6 & 0 & 2 & 1 & 13 & 1 \\
\hline$\%$ & $38.70 \%$ & $6.40 \%$ & $6.40 \%$ & $19.30 \%$ & 0 & $6.40 \%$ & $3.20 \%$ & $41.90 \%$ & $3.20 \%$ \\
\hline Opcão & $1,2,3$ & 1,3 & 1,3 & 1,3 & 0 & 2,3 & 2,3 & $1,2,3$ & 5 \\
\hline Total & 21 & 7 & 3 & 9 & 3 & 5 & 1 & 23 & 9 \\
\hline \% Total & $33.80 \%$ & $11.20 \%$ & $4.80 \%$ & $14.50 \%$ & $4.80 \%$ & $8 \%$ & $1.60 \%$ & $37 \%$ & $14.50 \%$ \\
\hline Opção Total & $1,2,3,5$ & $1,3,5$ & $1,3,5$ & 1,3 & 1,5 & $1,2,3,5$ & 2,3 & $1,2,3,5$ & $1,3,5$ \\
\hline
\end{tabular}

Fonte: Marceli Aquino

$\mathrm{Na}$ oitava tarefa era esperado que os participantes optassem pela OP3 com PM wohl na primeira posição, isto é, na primeira oração. Nessa disposição, a PM evidenciava que, segundo as informações apresentadas no texto, era bem possível ou provável (afirmação fraca) que a academia seria o melhor lugar para o flerte. Na OP3, a PM enfatiza a probabilidade com relação a algo acontecer no local (academia). Já na OP5, a PM estaria enfatizando a possibilidade da ação, ou seja, flertar. A análise contextual evidencia que o tema dessa tarefa remete à academia e às ações realizadas nela. Logo, a OP3 parece mais adequada.

Essa formulação foi a mais escolhida (41\% total, $43 \% \mathrm{~N}, 39 \% \mathrm{NN})$, ficando a OP1 sem PM em segunda colocação ( $37 \%$ total, $46 \%$ N, 30\% NN). Em todos os contextos nota-se que os participantes selecionaram a opção sem PM com frequência semelhante, assim, é provável que essa escolha não seja baseada apenas em expertise.

A justificativa de impressão, isto é, a sensação como suporte de escolha, foi a mais comum $(33,8 \%$ total, $38,7 \% \mathrm{~N}, 29 \% \mathrm{NN})$. No entanto, o tema mais comentado focava no significado da PM na OP3 (37\% total, 41,9\% N, 32,2\% NN). Além disso, os participantes tiveram dificuldade na tomada de decisão, o que pode indicar a necessidade do enfoque no ensino da PM wohl dependente tanto do contexto, da sua função nuclear, como da posição na oração. 
Aquino, M. - O questionário como ferramenta de ensino

9. Der Junge spielt mit dem Ball im Garten und trifft die Blumen seiner Mutter. Das

war nicht das erste Mal, sodass die Mutter sehr wütend ist und sagt:

OP1: Du bist wohl ein Elefant!

OP2: Du bist ein Elefant!

OP3: Du bist doch ein Elefant!

OP4: Du bist aber ein Elefant!

Warum haben Sie sich für diese Formulierung(en) entschieden?

Figura 9: Contexto 9

Fonte: Marceli Aquino

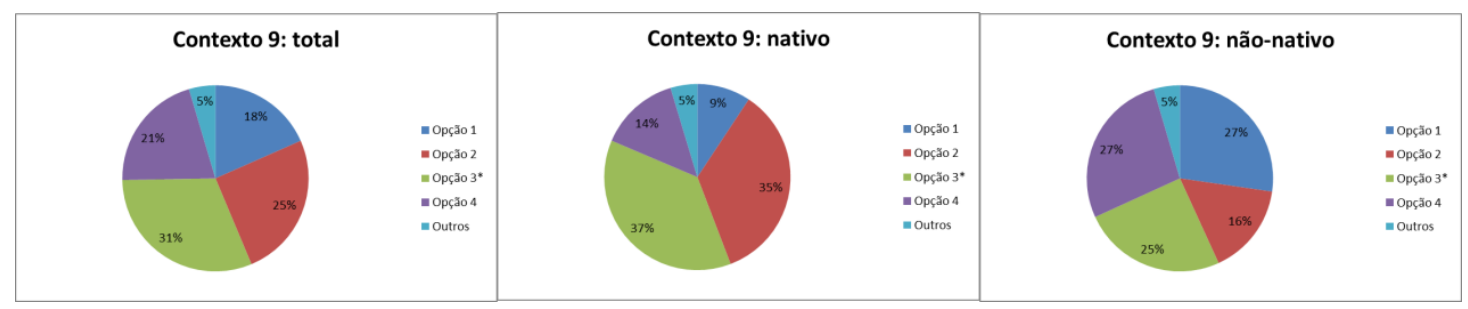

Gráfico 9: Porcentagem de escolhas totais e por grupo ( $\mathrm{N}$ e $\mathrm{NN})$

Fonte: Marceli Aquino

Tabela 9

Temas mais recorrentes nas justificativas de $\mathrm{N}$ e NN

\begin{tabular}{|c|c|c|c|c|c|c|c|c|}
\hline Participante & Impressão & Não sei & Com PM & Sem PM & Contexto & Wohl & Doch & Aber \\
\hline NN & 9 & 1 & 2 & 6 & 1 & 8 & 8 & 6 \\
\hline$\%$ & $29 \%$ & $3.20 \%$ & $6.40 \%$ & $19.30 \%$ & $3.20 \%$ & $25.80 \%$ & $25.80 \%$ & $6.40 \%$ \\
\hline Opcão & $1,2,3,4,5$ & 4 & $1,2,3,4$ & $2,4,5$ & 2,4 & $1,3,4$ & 1,3 & $1,2,4$ \\
\hline $\mathbf{N}$ & 8 & 1 & 0 & 9 & 2 & 2 & 11 & 4 \\
\hline$\%$ & $25.80 \%$ & $3.20 \%$ & 0 & $29 \%$ & $6.40 \%$ & $6.40 \%$ & $35.40 \%$ & $12.90 \%$ \\
\hline Opcão & $1,2,3$ & 2 & 0 & $1,2,3,4,5$ & $1,2,3,4$ & $1,2,3,4, S$ & $2,3, S$ & $3,4,5$ \\
\hline Total & 17 & 2 & 2 & \begin{tabular}{|l|}
15 \\
\end{tabular} & 3 & 10 & 19 & 10 \\
\hline \% Total & $27.40 \%$ & $3.20 \%$ & $3.20 \%$ & $24.20 \%$ & $4.80 \%$ & $16.10 \%$ & $30.60 \%$ & $16.10 \%$ \\
\hline Opção Total & $1,2,3,4,5$ & 2,4 & $1,2,3,4$ & $1,2,3,4,5$ & $1,2,3,4$ & $1,2,3,4, S$ & $1,2,3,5$ & $1,2,3,4,5$ \\
\hline
\end{tabular}

Fonte: Marceli Aquino

A formulação esperada na OP3, com PM doch, foi a mais escolhida (31\% total, $37 \%$ N, $25 \% \mathrm{NN})$. A segunda opção foi a OP2semPM (25\% total, 35\% N, 16\% NN). As justificativas para a escolha da PM doch voltavam-se à sua finalidade de expressar intensidade e frustração. A PM manifestava a falta de consideração do filho com relação às plantas da mãe. O segundo motivo de escolha foi a impressão. Outras $24 \%$ das justificativas consideravam que, nesse contexto, não seria necessário o uso de uma PM, apresentando um significado mais neutro. Alguns participantes julgaram errado que uma mãe chamasse o filho de elefante, então preferiram optar pela escolha sem PM, para que a asserção soasse menos pejorativa. 
Aquino, M. - O questionário como ferramenta de ensino

Uma das funções das PMs é destacar a informação importante para a comunicação; ela evidencia que aquele input é relevante e precisa ser considerado. Comparações entre sentenças com e sem PM permitem facilmente demonstrar que quando esse elemento é utilizado, o emissor consegue imediatamente sinalizar que alguma informação contextual precisa ser levada em consideração, destacando, assim, a sua relevância para implicar efeitos cognitivos. Nesse sentido, as questões apresentadas nas justificativas podem servir como ferramentas para debater as funções das PMs dentro de contextos diversificados e a diferença entre enunciados com e sem PMs. Ademais, situações culturais, como a mencionada acima, podem ser abordadas na busca por expressões em português que expressem tais atitudes e intenções.

\footnotetext{
10. Das Ausscheiden der Brasilianer im WM-Halbfinale gegen Deutschland war so heftig, dass die Südamerikaner noch immer darunter leiden. Im umgekehrten Fall hätte das hier ein fürchterliches Geschrei gegeben, aber heute würde in Deutschland kaum noch jemand darüber reden. So unterschiedlich sind eben die Fußball-Mentalitäten.

OP1: Es ist ja nur Fußball und nichts lebenswichtiges, aber in Brasilien sieht man das anders, man muss dort geboren sein, um das zu verstehen.

OP2: Es ist ja nur Fußball und nichts lebenswichtiges, aber in Brasilien sieht man das anders, man muss ja dort geboren sein, um das zu verstehen.

OP3: Es ist ja nur Fußball und nichts lebenswichtiges, aber in Brasilien sieht man das anders, man muss wohl dort geboren sein, um das zu verstehen.

OP4: Es ist ja nur Fußball und nichts lebenswichtiges, aber in Brasilien sieht man das anders, man muss doch dort geboren sein, um das zu verstehen.
}

Warum haben Sie sich für diese Formulierung(en) entschieden?

Figura 10: Contexto 10

Fonte: Marceli Aquino

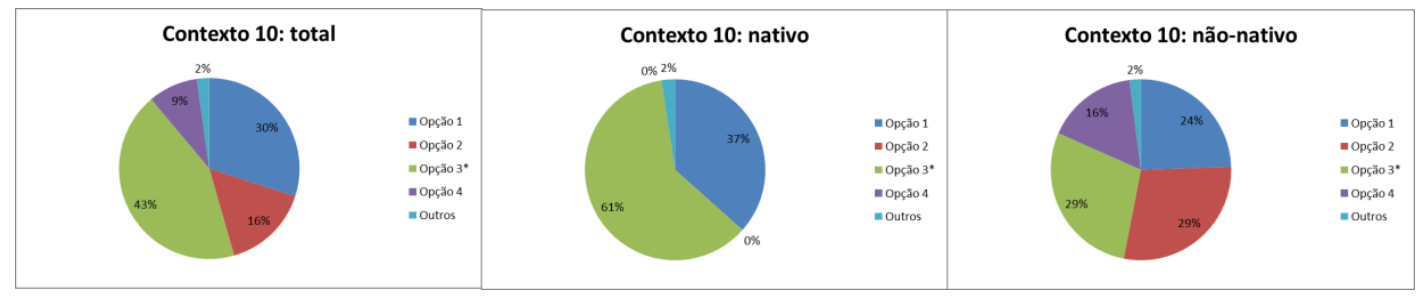

Gráfico 10: Porcentagem de escolhas totais e por grupo ( $\mathrm{N}$ e NN)

Fonte: Marceli Aquino 
Aquino, M. - O questionário como ferramenta de ensino

Tabela 10

Temas mais recorrentes nas justificativas de $\mathrm{N}$ e NN

\begin{tabular}{|c|c|c|c|c|c|c|c|c|c|}
\hline Participante & Impressão & Correto & Não sei & Todos & Sem PM & Contexto & Ja & Doch & Wohl \\
\hline NN & $\mathbf{1 1}$ & $\mathbf{3}$ & $\mathbf{6}$ & $\mathbf{4}$ & $\mathbf{3}$ & $\mathbf{3}$ & $\mathbf{4}$ & $\mathbf{1}$ & $\mathbf{6}$ \\
\hline$\%$ & $35.40 \%$ & $9.60 \%$ & $19.30 \%$ & $12.90 \%$ & $9.60 \%$ & $9.60 \%$ & $12.90 \%$ & $3.20 \%$ & $19.30 \%$ \\
\hline Opcão & $1,2,3,4$ & 1,3 & $1,2,3,4$ & $1,2,3,4$ & 1,3 & $1,2,3,4$ & $2,3,5$ & 4 & $1,2,3$ \\
\hline $\mathbf{N}$ & $\mathbf{1 0}$ & $\mathbf{2}$ & $\mathbf{3}$ & $\mathbf{0}$ & $\mathbf{6}$ & $\mathbf{1}$ & $\mathbf{2}$ & $\mathbf{0}$ & $\mathbf{1 7}$ \\
\hline$\%$ & $32.20 \%$ & $6.40 \%$ & $9.60 \%$ & 0 & $19.30 \%$ & $3.20 \%$ & $6.40 \%$ & 0 & $54.80 \%$ \\
\hline Opcão & 1,3 & 1 & 1,3 & 0 & 1,3 & 3 & 1,3 & 0 & $1,3, \mathrm{~S}$ \\
\hline Total & $\mathbf{2 1}$ & $\mathbf{5}$ & $\mathbf{9}$ & $\mathbf{4}$ & $\mathbf{9}$ & $\mathbf{4}$ & $\mathbf{6}$ & $\mathbf{1}$ & $\mathbf{2 3}$ \\
\hline \% Total & $\mathbf{3 3 . 8 0} \%$ & $\mathbf{8} \%$ & $\mathbf{1 4 . 5 0} \%$ & $\mathbf{6 . 4 0}$ & $\mathbf{1 4 . 5 0 \%}$ & $\mathbf{6 . 4 0} \%$ & $\mathbf{9 . 6 0 \%}$ & $\mathbf{1 . 6 0 \%}$ & $\mathbf{3 7 \%}$ \\
\hline Opção Total & $1,2,3,4$ & 1,3 & $1,2,3,4$ & $1,2,3,4$ & 1,3 & $1,2,3,4$ & $1,2,3, \mathrm{~S}$ & $\mathbf{4}$ & $1,2,3, \mathrm{~S}$ \\
\hline
\end{tabular}

Fonte: Marceli Aquino

Na última tarefa, os participantes optaram pela OP3 com PM wohl (43\% total, 61\% N, $29 \%$ NN). Novamente, a seleção da oração sem PM (OP1)foi recorrente (30\% total, 37\% $\mathrm{N}, 24 \% \mathrm{NN})$. Juntamente com a reflexão sobre o significadoda PM wohl, isto é, suposição ou incerteza (37\% total, $54,8 \% \mathrm{~N}, 19,30 \% \mathrm{NN})$, asmenções àfalta de conhecimento também foram frequentes nessa tarefa (33,8\% impressão, 14,5\% não sei), que possivelmente refletiramnas escolhas das opções sem PM.

Os resultados encontrados nesse e nos outros contextos parecem corroborar a conjectura de que as PMs devem e podem ser abordadas com maior ênfase em sala de aula. Os dados coletados, especialmente as justificativas, indicam que tanto os grupos iniciantes de alemão, como os mais avançados, precisam ser apresentados a casos de estudo com PMs em diversos contextos. O foco na função nuclear de cada PM parece ser a solução mais adequada para o desenvolvimento do conhecimento e identificação desses elementos modais. Além do contraste entre elementos modais e seus homônimos não modais, práticas de discussão e comparação entre as funções e ocorrências dasPMssão benéficas para o ensino de línguas.

O gráfico a seguir mostra os resultados quanto à comparação entre os grupos de participantes, ao selecionar as respostas esperadas por contexto. 
Aquino, M. - O questionário como ferramenta de ensino

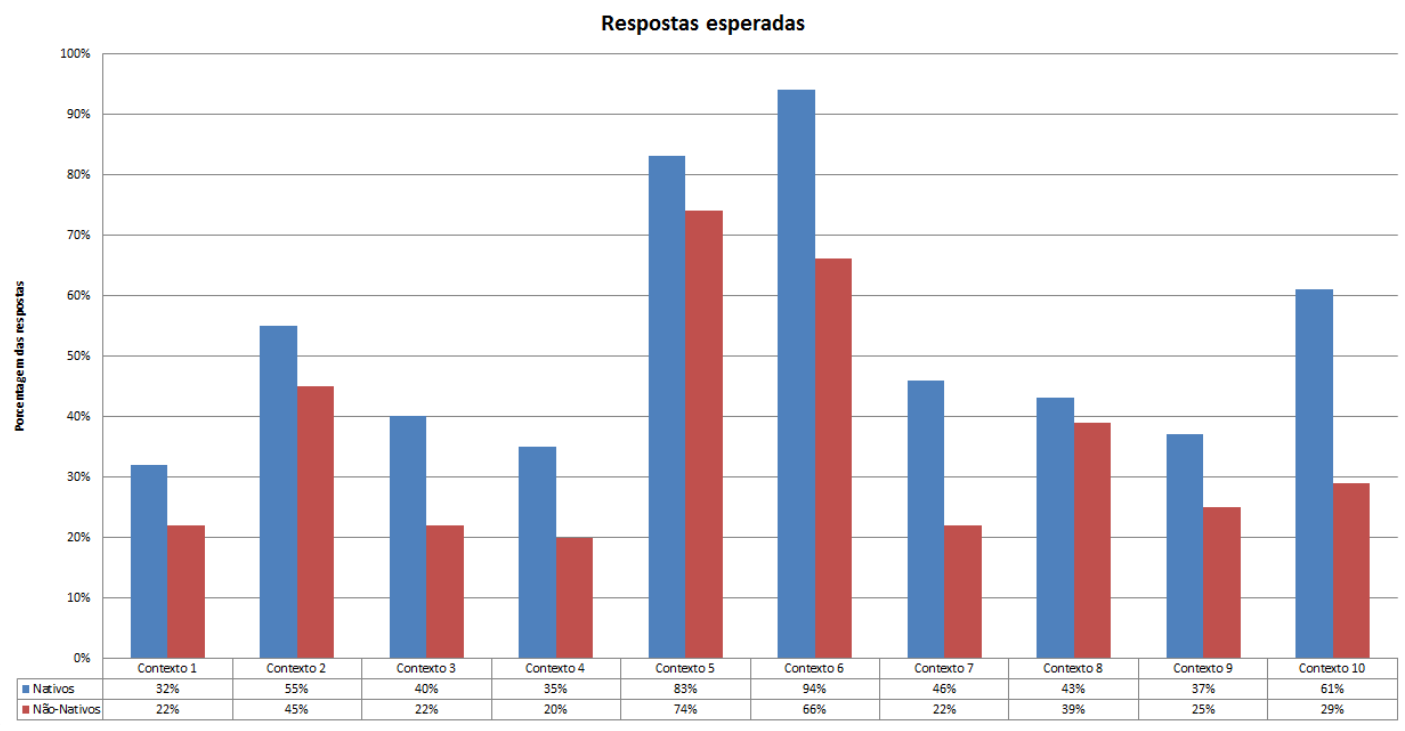

Gráfico 11: Frequência de respostas esperadas por contexto e por grupo (N e NN)

Fonte: Marceli Aquino

Os resultados do gráfico corroboram as informações obtidaspela análise das dez tarefas. Em todos os contextos, os nativos foram os que mais selecionaram as respostas esperadas. Mesmo não sendo tão expressiva, a diferença entre os grupos parece confirmar o que foi discutido na introdução, isto é,que as PMs são imediatamente reconhecidas e processadas pelos nativos, uma vez que essas informações fazem parte de seu ambiente cognitivo. Já os participantes não nativos apresentaram maior dificuldade em reconhecer as funções e usos das PMs.

Porém, a diferença entre os dois grupos, no momento de justificar suas escolhas dentro de contextos específicos, não foi tão significativa quanto se imaginava. Com grande frequência, a seleção das opções adequadas baseou-se na impressão, ou seja, intuição do que soa melhor (alguns até comentaram que falaram alto para verificar).

Esse resultado está de acordo com o que é conhecido e discutido sobre a função e o significado das PMs. A modalidade pode ser caracterizada como a função mais complexa das categorias linguísticas conhecidas pela espécie humana (LEISS 2012), e as PMs são os casos mais complexos de modalidade. Assim, parece natural que os participantes, mesmo os nativos, tenham dificuldade em justificar e explicar as suas escolhas. Não obstante, esse resultado também indica a necessidade de abordar o tema em sala de aula de maneira mais concreta, com a descrição das funções, ocorrências e as características sintáticas e semânticas de cada partícula. 


\section{Conclusão}

Sabemos que a TR postula que a cognição humana se orienta pela relevância ótima, isto é, a nossa compreensão direciona-se às informações que nos parecem relevantes. Nesse sentido, as PMs são elementos que evidenciam referências relevantes no discurso, a atitude e a intenção do emissor. A reflexão principal deste trabalho defende que, se as PMs forem interpretadas de maneira eficaz, elas podem gerar um grande efeito cognitivo, adquirindo a função de pistas comunicativas necessárias para a troca entre ambientes cognitivos.

De acordo com os postulados relevantistas, os resultados apontam para uma maior seleção de respostas esperadas por parte dos participantes nativos. Esses dados corroboram os obtidos em AQUINO (2016), segundo os quais o processamento de nativos alemães, em contraste com brasileiros, exige um menor esforço cognitivo, porém sem alcançar efeitos contextuais adequados. ${ }^{7}$ No entanto, as justificativas oferecidas nas tarefas dos questionários, pelos dois grupos, revelam a dificuldade em reconhecer a função das PMs. Esse resultado pode caracterizar uma deficiência na aprendizagem da função e complexidade modal destes elementos.

Pela complexidade do processo inferencial envolvendo as PMs e a importância para a relação social e comunicativa em língua alemã, a sua análise deve essencialmente levar em consideração diferentes aspectos, como o contexto, a função comunicativa núcleo, as intenções e expectativas dos interlocutores. Tendo-se em mente que, mesmo existindo elementos modais em outras línguas (como no português), a interpretação das PMs alemãs pode advir de um processamento diferente, exigindo estratégias e habilidades que envolvam níveis cognitivos mais altos.

Em vista disso, este trabalho oferece uma investigação com percepções de contextos linguísticos e extralinguísticos diferenciados, podendo assim, obter resultados com maior validade para a pesquisa com PMs. Procuramos incentivar e oferecer ferramentas para a discussão da função, significado, posição e ocorrências das PMs doch, wohl, aber e ja. O enfoque nas funções comunicativas das PMsoferece estratégias vantajosas para desenvolver atividades dinâmicas e objetivas em sala de aula de língua

\footnotetext{
${ }^{7}$ A TR defende que qualquer processo inferencial está voltado a alcançar produtividade cognitiva, isto é, gerar o máximo de efeitos contextuais, com o mínimo de esforço cognitivo necessário (SPERBER; WILSON 1995). Os efeitos contextuais representam o resultado da interação entre as informações novas e dadas, como o resultado dos próprios processos inferenciais (GONÇALVES 2005: 140).
} 
Aquino, M. - O questionário como ferramenta de ensino

alemã. Logo, com a análise de dados do questionário foi possível aprofundar o conhecimento do uso, funções no discurso e significados que esses elementos podem adquirir em diferentes contextos e posições.

\section{Referências bibliográficas}

ABRAHAM, Werner. Introduction. In: ABRAHAM, Werner (Ed.). Discourse particles. Descriptive and theoretical investigations on the logical, syntactic, and pragmatic properties of discourse particles in German. Amsterdam: John Benjamins, 1991a. p. 1-10.

ABRAHAM, Werner. Discourse Particles in German: How does their illocutive force come about? In: ABRAHAM, Werner (Ed.). Discourse particles. Descriptive and theoretical investigations on the logical, syntactic, and pragmatic properties of discourse particles in German. Amsterdam: Benjamins, 1991b. p. 203-252.

AQUINO, Marceli. A função dinâmica das partículas modais alemãs doch $e$ ja no ensino de línguas.2012. 110 f. Dissertação (Mestrado em Estudos Linguísticos) - Faculdade de Letras, Universidade Federal de Minas Gerais, Belo Horizonte, 2012a.

AQUINO, Marceli. A força comunicativa das partículas modais alemãs no ensino de línguas. Diálogo das Letras, Pau dos Ferros, v. 1, n.2,p. 103-115,2012b.

AQUINO, Marceli. O esforço de processamento das partículas modais doch e wohl em tarefas de pós-edição: uma investigação processual no par linguístico alemão/português. Tese (Doutorado em Estudos Linguísticos) - Faculdade de Letras, Universidade Federal de Minas Gerais, Belo Horizonte, 2016.

AQUINO, Marceli. O processamento das partículas modais alemãs em tarefas de pós-edição. Pandaemonium Germanicum, São Paulo, v. 20, n. 30, p. 65-85, 2017.

BuSSE, Dietrich (Hg.). Diachrone Semantik und Pragmatik. Untersuchungen zur Erklärung und Beschreibung des Sprachwandels. Tübingen: Niemeyer, 1991.

DIEWALD, Gabriele. Same same but different. Modal particles, discourse markers and the art (and purpose) of categorization. In: DEGAND, Liesbeth; PIETRANDREA, Paola; CORNILliE, Bert (Ed.). Discourse markers and modal particles. Categorization and description. Amsterdam/Philadelphia: John Benjamins, 2013. p. 19-46.

FISCHER, Kerstin; ALM, Maria. A radical construction grammar perspective on the modal particle-discourse particle distinction. In: DEGAND, Liesbeth; PIETRANDREA, Paola; CORNILliE, Bert (Ed.). Discourse markers and modal particles. Categorization and description. Amsterdam/Philadelphia: John Benjamins, 2013. p. 47-88.

FRANCO, António. Descrição linguística das partículas modais no português e no alemão. Coimbra: Coimbra, 1991.

GONÇALVES, José Luiz. Desenvolvimento da pragmática e a teoria da relevância aplicada à tradução.Linguagem em (Dis)curso, Tubarão, v. 5,número especial, p. 129-150, 2005.

HELBIG, Gerhard. Lexikon deutscher Partikeln. 2.ed. Leipzig: Enzyklopädie, 1990.

HERINGER, Hans Jürgen. Lesen, lehren, lernen. Eine rezeptive Grammatik des Deutschen. Tübingen: Max Niemeyer, 1988.

JoHnEn, Thomas. Aí como partícula modal do português. In: MotA, Jacyra (Ed.). Atas do $1^{0}$ Congresso Internacional da Associação Brasileira de Lingüística. Salvador: Instituto de Letras da Universidade Federal da Bahia, 1997.v. 2:Comunicações, disquete 6: Lexicologia e Semântica,p. 5-10.

KRIVONOSOV, Aleksej. Zum Problem der Klassifizierung der deutschen Partikeln. In: WEYDT, Harald. Sprechen mit Partikeln. Berlin: De Gruyter, 1989. p. 30-38. 
Aquino, M. - O questionário como ferramenta de ensino

KRÖLL, Heinz. Die Ortsadverbien im Portugiesischen unter besonderer Berücksichtigung ihrer Verwendung in der modernen Umgangssprache. Mainzer Romanistische Arbeiten. Wiesbaden:Franz Steiner, 1968.

LEISS, Elisabeth. Epistemicity, evidentiality, and Theory of Mind (ToM). In: ABRAHAM, Werner; LEISS, Elisabeth (Ed.). Modality and theory of mind:elements across languages. Berlin: De Gruyter, 2012. p. 37-66.

LINDNER, Katrin. 'Wir sind ja doch alte Bekannte'. The use of German ja and doch as modal particles. In: ABRAHAM, Werner (Ed.). Discourse particles. Descriptive and theoretical investigations on the logical, syntactic, and pragmatic properties of discourse particles in German.Amsterdam: John Benjamins, 1991. p. 163-201.

MANOEL, Célia. As partículas modais alemãs:uma exemplificação com doch. 1998. $90 \mathrm{f}$. Dissertação (Mestrado em Língua e Literatura Alemã) - Faculdade de Filosofia, Letras e Ciências Humanas, Universidade São Paulo, São Paulo, 1998.

MöLLERING, Martina. Teaching German modal particles: a corpus-based approach. Language, Learning \& Technology, v. 5, n. 3, p. 130-151, 2001.

NUNES, Elaine. As partículas modais da língua alemã: um problema para a tradução? Um estudo com base nos contos Nachts schlafen die Ratten doch de Borchert e Berlin Bolero de Schulze.2008. 125 f. Dissertação (Mestrado em Estudos da Tradução) Universidade Federal de Santa Catarina, Florianópolis, 2008.

PARASURAMAN, Ananthanarayanan. Marketing research.2. ed.New York:Addison WesleyPublishing Company, 1991.

RAMOS, Rui. As partículas modais como co-indicadores ilocutórios.O caso das perguntas retóricas. In: CASTRO, Rui Vieira de; BARBOSA, Pilar; GUIMARÃES, Zélia (Org.).Actas do XV Encontro Nacional da Associação Portuguesa de Lingüística. Braga: Associação Portuguesa de Lingüística, 2000.v. II,p. 225-242.

SAID ALI, Manuel. Meios de expressão e alterações semânticas. Rio de Janeiro: Livraria Francisco Alves, 1930.

SoUZA, Marilyn Landim de. Funções comunicativas de partículas modais alemãs em fóruns de discussão na internet.2008. 175 f.Dissertação (Mestrado em Língua e Literatura Alemã) - Faculdade de Filosofia, Letras e Ciências Humanas, Universidade São Paulo, São Paulo, 2008.

SPERBER, Dan; Wilson, Deirdre. Relevance: communication and cognition. 2. ed. Oxford (UK): Blackwell, 1995.

SPERBER, Dan; WILSON, Deirdre. Teoria da Relevância. Linguagem em (Dis)curso, Tubarão, v. 5, número especial, p. 221-268, 2005.

TraugotT, Elizabeth Closs. Discussion article: Discourse markers, modal particles and contrastive analysis, synchronic and diachronic. Catalan Journal of Linguistics, v. 6, p. 139-157,2007.

WALTEREIT, Richard. Different functions, different histories. Modal particles and discourse markers from a diachronic point of view. Catalan Journal of Linguistics, v. 6, p. 61$80,2007$.

WELKER, Herbert. As partículas modais no alemão e no português e as equivalências de aber, eben, etwa $e$ vielleicht. Dissertação (Mestrado em Linguística) - Departamento de Linguística, Universidade de Brasília, Brasília (DF), 1990.

WEYDT, Harald(Hg.). Partikeln und Interaktion. Tübingen: Niemeyer, 1983.

Recebido em 12/04/2017

Aceito em 30/05/2017 